\title{
Máscaras y Más Máscaras
}

Frente a la palabra polisémica la noción de que la función de la crítica literaria es la de iluminar el texto parecería tal vez excesivamente presuntuosa. En cambio juzgaría más adecuada la afirmación de que cada lectura es una nueva escritura (de muchas otras posibles) de un texto. Consciente entonces de las limitaciones de cualquier acto crítico, este ensayo intentará una lectura-escritura de Martín Fierro que desenmascare progresivamente la escritura, señalando cómo la palabra plurideterminada se vuelve irónica, humorística, paródica, satírica, es decir, polivalente al participar de un diálogo inter e intratextual. ${ }^{1}$

Hubo, como se sabe, aquel escritor argentino llamado José Hernández que leyó textos literarios de Bartolomé Hidalgo e Hilario Ascasubi, Los tres gauchos orientales de Antonio Lussich, y Fausto de Estanislao del Campo, y que también leyó la historia de su país y la sociedad de su época como textos, pero él permanece afuera del texto que escribió, porque "Ia seule manière qu'a l'écrivain de participer à l'histoire devient alors... par une écriture-lecture, c'est-a-dire par une pratique d'une structure signifiante en fonction de ou en opposition avec une autre structure."2 Asi es que en 1872 publicó la primera parte de un texto llamado Martín Fierro, que completó con La vuelta de Martín Fierro en 1879, y murió en La Plata en 1886.

Además del autor histórico de Martin Fierro, hay y hubo desde que se publicó, ávidos lectores del texto. Entre ellos figura un tal Juan María Torres que en una carta a José Hernández del 23 de febreto de 1873, escribe entre solipsístico y tautológico: "Para que Martin Fierro pudiera ser objeto de crítica, era preciso que fuera una obra de arte, sujeta a sus reglas y por consiguiente a su aplicación -o siéndolo- no pueden aplicársele, luego no puede hacerse un juicio crítico sobre ella". ${ }^{3}$ Estos lec-

1 Para los conceptos de inter $e$ intratextualidad, véase el ensayo de Severo Sarduy, "El barroco y el neobarroco", América Latina en su literatura (México: Editorial Siglo XXI, 1972), p. 167:184.

2 Julia Kristeva, "Bakhtine, le mot, le dialogue, et le roman", Critique, XXIII (avril 1967), núm. 239, p. 439.

${ }^{3}$ Siento no tener más en mis manos una de esas ediciones populares origi- 
tores históricos tampoco tienen lugar en el espacio textual. Hay, en suma, un autor y lector históricos que permanecen afuera del espacio textual. Por lo tanto, si bien lo dicho hasta ahora ayuda a ubicar el texto en un espacio histórico, no atañe a un análisis del texto en sí.

Dentro del texto mismo se encuentra lo que se ha llamado el autor implícito: el texto es el producto de lo que él selecciona y evalúa, "él es el que elige, consciente o inconscientemente, lo que leemos; lo imaginamos como la versión ideal, literaria, creada del hombre verdadero: es la suma total de sus propias selecciones." 4 A esa versión ideal, literaria del autor que escribió Martín Fierro habría que imaginarlo como un individuo que simpatizaba con los gauchos, que los tomaba en serio, y que además escribía desde el punto de vista de un gaucho, asumiendo el tono de voz hablado del gaucho. Es decir que el culto escritor José Hernández asumió la persona del gaucho para escribir su texto: se colocó una máscara opaca, para disimular su cara y su voz. En esto Matrtín Fierro entronca con una tradición de literatura gauchesca ya existente en el Río de la Plata, tradición que encierra una doble parodia: en primer lugar parodia del habla, ya que el gaucho en realidad no hablaba en verso; y en segundo lugar parodia del canto del gaucho, ya que cuando cantaba, en realidad, el gaucho trataba de asumir una voz más oculta. Reconocida su presencia, queda por situar a ese autor implícito en el espacio textual.

Al final de la primera parte de Martín Fierro, llamada El gaucho Martín Fierro, aparece un narrador dramatizado, en un espacio que a primera vista parece ambiguo. Los narradores dramatizados que habían hablado hasta ese momento eran claramente Martín Fierro y Cruz, pero en los versos culminantés de la historia otro narrador asume la voz en primera persona y se conviette él en espectador y auditor de Martín Fierro: "En este punto el cantor/ Buscó un porrón pa consuelo,/ Echó un trago como un cielo,/ Dando fin a su argumento;/ $\mathrm{Y}$ de un golpe al instrumento/ Lo hizo astillas contra el suelo."5. Este narrador no sólo toma el hilo de la narración, sino que se apropia del texto como suyo: "Y daré fin a mis coplas/ Con aire de relación" (1. 2281-2282); y se revela consciente de un público presente, al que se dirige para referirse al contenido de su texto; "Y ya con estas noticias/ Mi relación acabé;/ Por ser ciertas las conté/ Todas las desgracias dichas:/ Es un telar de

nales', de Martín Fierro que traen en su introducción la crítica contemporánea a la publicación del texto.

${ }_{4}$ Wayne C. Booth, The Rbetoric of Fiction (London: University of Chicago Press, 1961), p. 74-75, traducción mía.

5 José Hernández, Martín. Fierro, 4a. edición crítica de Carlos Alberto Leumann. (Buenos Aires: Angel Estrada y Cía., S. A., 1961), 1. 2269-2274. 
desdichas/ Cada gaucho que usté ve/ Pero ponga su esperanza/ en el Dios que lo formó" (1. 2305-2310). Como explica Muecke, "Irony is a double-layered or two-story phenomenon:"'6 a nivel de autor implícitotexto se ha hecho un exposé de la autoridad (detrás de la cual está el gobierno formado por hombres cultos), pero a nivel de la relación narrador dramatizado-lector implícito, el autor finge inocencia: "Estas noticias... Por ser ciertas las conté." La inocencia del narrador queda, como se verá, invalidada por su escritura: para exponer, criticar, avergonzar la vida humana, la sátira hace de cuenta de que lo que relata es la verdad desnuda ("noticias... ciertas"), pero lo que en efecto realiza es una apro. priación de recursos especiales para describir con la mayor claridad posible una situación dolorosa y absurda. ${ }^{7}$ Es decir que a otro nivel la máscara de periodista que se pone el narrador para el lector implícito queda invalidada por los recursos que aparecen en su texto, que deforman las "cosas ciertas", y que incluyen la caricatura, la parodia, la ironía. Por otro lado, la inocencia de cierto lector implícito que quiere "saber/ Cómo fué la conclusión" al que el autor dramatizado, para más, incita a que "ponga su esperanza/ En el Dios que lo formó" (1. 2311-2312), queda invalidada por lo que deja de hacer frente al "telar de desdichas" que se le ha presentado, porque él es cómplice en la creación de ese telar.

Parecería ser ese mismo autor implícito el que aparece como narrador en tercera persona en La vuelta de Martín Fierro. Introduce y despide el relato de Picardía (XX y XXIX), despedida que coincide con la presentación del Moreno y su desafío a Martín Fierro. También describe la conclusión de la payada entre el Moreno y Martín Fierro. El papel del narrador aquí es de informat al público lector, eslabonando un episodio con otró. Lo hace en un espacio textual ambiguo en que no se sabe si forma parte del público gaucho espectador de ese incidente o si es un narrador que está contando toda la ficción y aflora a la superficie del texto sólo en esos momentos. Su papel se aclara al final de la obra cuando describe la separación de los cuatro gauchos. Entonces vuelve a asumir la voz de narrador en primera persona que se apropia del texto como suyo y está consciente de un público lector: "Y ya dejo el estrumento/ Con que he divertido a zstedes" (2. 4799-4800). Estrumento es significante ambiguo que admite varios significados dentro del contexto del texto, pudiendo significar el instrumento musical con que acompañaría las coplas, la voz como instrumento de su canto, la lapicera' con que escribe, o la escritura

- D. C. Muecke, The Compass of Irony (London: Methuen \& Co. Ltd., 1969), p. 19

7 Para este concepto de sátira, véase a Gilbert Highet, The Anatomy of Sative (Princeton: Princeton University Press, 1962), p. 18-23. 
que se refiere a sí misma como algo ya completo, un instrumento para algo, "No se ha de llover el rancho/ En donde este libro esté" (2. 4857. 4858). La identidad del lector implícito en ese wstedes se hace doble en esta segunda parte de Martín Fierro (La vielta de Martín Fierro): el narrador, en contraste con su identidad más vaga en la primera parte del texto, ahora se identifica con uno de los lectores implícitos, cuyo nombre revela: gaucho, paisano, "Pues son mis desdichas/ Las de todos mis hermanos:/ Ellos guardarán ufanos/ En su corazón mi historia" (2. 4877-4880), y al que insinúa una cierta lectura de Martin Fierro como parodia de su propia vida. En oposición a ese primer lector aflora un segundo lector al que sólo se describe, sustituyéndose su nombre por un pronombre, permitiéndole cierta anonimidad, "Y aquéllos que en esta historia/ Sospechen que les doy palo/ Sepan que olvidar lo malo/ También es tener memoria" (2. 4885-4888). El significante ausente, sin embargo, ya se ha nombrado a otros niveles del texto, y es fácil identificarlo como la autoridá. La máscara de gaucho que había usado el narrador le permitió mostrar el contexto con cierto aire de inocencia: la autoridad podía hacer oídos sordos al relato de un individuo marginalizado como el gaucho. Ese estado de la escritura que se suponía válida, sin embargo, se corrige en el proceso de desenmascaramiento: se revela detrás de la máscara de gaucho, otra cara y una voz culta que exige cambios sociales, "Debe el gaucho tener casa/ escuela, iglesia y derechos. . Sepan que olvidar lo malo/ También es tener memoria" (2. 4827-4828. . 4887-4888) : es la voz satírica que se oye detrás de una de sus máscaras especiales, la ironía. ${ }^{8}$ Al lector implícito culto se le está indicando otra lectura: la de Martín Fierro como una sátira velada de la corrupción de los que representan al hombre culto para el gaucho, la autorida. Si "parody is the masked servant of satire"' a este nivel del texto la máscara paródica se transparenta y deja entrever la cara del amo: la sátira, cuyo móvil más poderoso es el odio basado en un juicio moral, lo cual a su vez encierra la esperanza de lograr reformas, es decir, una mejor vida para el gaucho.

Se ha hablado de narrador dramatizado y de autor implícito como si fueron sinónimos, y creo que ahora es lícito afirmar esa coincidencia. Referido al espacio textual, el autor implícito, que coincide con uno de los narradores dramatizados, se ubicaría como autor de un texto escrito ("este libro") en el que un gaucho principal llamado Martín Fierro, junto con otros gauchos, cantan sendas historias a un público de uno o más gauchos y en que ellos son los respectivos protagonistas.

8 Highet, p. 55.

$\theta$ Highet, p. 140. 
Ubicado el autor implícito y el doble lector implícito en el espacio textual cabe señalar cómo Martin Fierro es una respuesta del autor implícito a otros textos que quedan en filigrana en su texto. Como respuesta a la sociedad leida como texto, ya se ha mencionado que Martín Fierro entronca con una tradición de literatura gauchesca en que el texto es una parodia a nivel del lenguaje y cantos gauchescos. Además, al imitar la manera de pensar y sentir del gaucho se crea una parodia del personaje real. Como parodia de Fausto de Estanislao del Campo, Martín Fierro habla seriamente del gaucho (como lo hace Lussich), parodia que implica un elogio del gaucho, mientras que el desprecio que implica esa parodia se dirige hacia la sociedad que lor marginalizó.

En relación a su propio texto, el autor implícito es una suerte de dramaturgo que permite que los personajes de su texto se revelen, sin comentario, en su situación irónica. El es el titiritero, y el primer títere que presenta sobre el escenario, Martín Fierro, dice, "Soy gaucho, y entiendaló:" palabras que identifican al personaje que se sitúa ante un público formado por una persona más (verbo en singular: entiéndaló). En su canto Martín Fierro entremezcla una descripción quejumbrosa de la condición del gaucho con una ficción sobre su propia vida de gaucho. Este gaucho cantor también lleva una máscara irónica. Veamos cómo funciona la ironía dentro de la ficción en que Martín Fierro es el protagonista. Ante todo, la ironía supone dos niveles de significación, en que un nivel invalida al otro, de ahí que la palabra se vuelva ambigua y ambivalente. Martín Fierro se representa al principio de su ficción como la víctima inocente, que no tiene conciencia de su dilema; cuando el Juez de Paz "hizo una arriada en montón" (1.312) dice Martín Fierro, "Yo no quise disparar/ Soy manso- y no había porque;/ Muy tranquilo me quedé/ $\mathrm{Y}$ ansí me dejé agarrar" (1. 315-318). La leva lo arrancó de su vida arcádica y lo mandó a la frontera a luchar contra el indio, aunque "Al mandarnos nos hicieron/ Más promesas que a un altar,/ El Juez nos jué a proclamar/ Y nos dijo muchas veces:/ 'Muchachos, a los seis meses/ Los van a it a revelar'" (1. 355-360). Dentro de la ficción de Martín Fierro, el Juez de Paz es el primer ironizador, al practicar la decepción, y el gaucho es su víctima. $\mathrm{La}$ ironía se produce al invalidarse las promesas del Juez cuando se las superpone a lo que de hecho ocurrió. Paulatinamente la vida de Martín Fierro sufrió una espantosa acumulación de situaciones irónicas en la frontera. El era siempre la víctima, aunque los victimizadores variaran del pulpero que "Nos tenía apuntaos a todos/ Con más cuentas que un rosario" (1. 709-710) al comandante que le quitó el "moro" ganado a un indio, al comisario que no aparecía con el salario, "Pero sabe Dios qué zorro/ Se lo comió 
al Comisario" (1. 713-714); y a lo lejos estaba el gobierno, "La pucha que se trabaja/ Sin que le larguen ni un rial./ ...Si eso es servir al Gobierno,/ A mí no me gusta el cómo" (1. 425-426. . 431-432).

Se debe tener presente que desde su tiempo y espacio de cantor, Martín Fierro ya se conoce toda la historia que está contando. Su intención declarada es consolarse con el canto: "Que el hombre que lo desvela/ Una pena estrordinaria/ Como la ave solitaria/ Con el cantar se consuela" (1. 3-6), primer nivel de una ironía, porque en su canción, en efecto, lo que hace es descubrir, exhibir, poner en plena escena la corrupción de la 'autoridá', desenmascarándola. Es decir que lo revelado en la ficción invalida lo declarado en el canto y los papeles se invierten, ya que Martín Fierro es ahora el ironizador y la 'autoridá' su víctima.

La frontera en que se encontró Martín Fierro en su ficción, no sólo era geográfica, espacial, porque coincidía además con la frontera que separa vida y muerte. Tal vez los dos momentos más humorísticos del episodio en la frontera geográfica ocurrieton cuando el protagonista se encontró empujado por las circunstancias tenebrosas en que subsistía a balancearse sobre el umbral mismo que media entre vida y muerte. El primer suceso tuvo que ver con el encuentro con un indio en un malón, que no analizaré en este ensayo. El segundo incidente se produjo al darse Martín Fierro con la autoridad bajo la forma de aquel "pa po-litano" (1. 852). Aquí se está en el mundo de la pura "représentation deformée du réel, la caricature se nourrit des défauts physiques, intellectuels, ou moraux de ceux qu'elle prend pour cible.. Elle réclame, d'autre part, une exagération qui conduit au bouffon ou au monstrueux, sans tuer la ressemblance:"10 el emisario del hombre culto es un extranjero cuyo castellano no es del todo inteligible, y que para más, está borracho estando de guardia. A él tiene que responder el gaucho con su vida. La escena pertenece a esa categoría de caricatura que entretiene usando la ironía maliciosa por máscara. La incongruidad irónica ocurre a nivel de significante y significado; de lo que el gringo dijo: " 'Quén vivore' ...'Ha garto" " $(1.860 \ldots$ 862) y lo que quiso significar: ¿Quién vivie?... ¡Haga alto! Martín Fierro tomó el grupo de fonemas sin significado en español y los asoció maliciosamente con significantes de sonido parecido, convirtiendo una pregunta y una orden en insultos, a los que él responde: " 'Qué vívoras' ... 'Más lagarto serás vos" (1.861 ... 1.864). La ironía es abierta. No sólo es Martín Fierro víctima de la autoridad, sino que a su vez logra con el sarcasmo, convertir a la autoridad en víctima suya. Dentro de su misma ficción Martín Fierro es consciente de su doble

Ia Jean Pierre Cèbe, La caricatune et la parodie: dans le monde romain antique des origines a Juvénal (Paris: ed. E. de Boccard, 1966), p. 8. 
papel de víctima y caricaturizador de la autoridad. El juego de palabras permite la satisfacción de una ansia hostil a pesar de un obstáculo que lo impediría. ${ }^{11}$ El ansia hostil está dirigido a la autoridad que Martín Fierro desearía burlar. El obstáculo que lo impediría está concretizado en el fusil del gringo. El ingenio consigue eludir el impedimento, y ayudado por la oscuridad y la borrachera de la autoridad, se satisface, burlándose de las órdenes. El inconsciente que subtiende esa estructura es el sexo y la muerte: es en el momento en que Martín Fierro se da cuenta, "Que aquel mal no tiene cura,/ Que tal vez mi sepultura/ Si me quedo iba a encontrar" (1. 830-832) que aflora a la superficie del texto ese diálogo entre sexo y muerte: aparecen símbolos sexuales siniestros como el fusil (en manos de una autoridad con la que no se podía comunicar, por gringo y borracho), la víbora y el lagarto: muerte y sexo dialogan en un mundo fronterizo, al revés, carnavalesco, donde el cuerdo es el ser marginalizado y el loco la autoridad.

En la acumulación de ironías en la frontera, el protagonista sigue una trayectoria interior en que va tomando conciencia de su situación: deja de ser víctima inocente, que es el primer nivel de una dualidad irónica. En el segundo nivel de esa dualidad aparece una operación paradójica: Martín Fierro tiene que elegir entre convertirse en un desertor y salvar su vida, o quedarse al servicio de un gobierno totalmente vicioso y correr el riesgo de perder la vida. A primera vista la solución parece fácil: optar por la vida y escaparse de la frontera. La tensión síquica engendrada por la contradicción irónica, sin embargo, no se resuelve, porque la autoridad está en todas partes, y busca a los desertores. Tanto el observador (lector implícito) como el ironizador (Martín Fierro cantor) están comprometidos en la ironía. Se lo ve a la víctima como atrapada en una situación imposible. En este tipo de ironía doble hay una contradicción básica entre la naturaleza humana, representada por el deseo de Martín Fierro de regresar a su vida anterior, y la condición humana, encarnada en el gaucho perseguido por una ley injusta y corrupta. Falta el elemento de resolución, porque un nivel irónico no invalida al otro, por lo que la tensión engendrada en la situación irónica vital de Martín Fierro perdura hasta que decide cruzar la frontera, ir más allá de donde alcance la jurisdicción del gobierno que lo busca.

Cuando la 'autotidá' lo cerca a Martín Fierto en la noche, se le pliega Cruz. La historia de Cruz, canto y ficción, se incrusta en la ficción de Martín Fierro, y el cantor Martín Fierro desaparece hasta el

11 Estos conceptos se encuentran expuestos por Sigmund Freud, Wit and Its Relation to the Unconscious en The Basic Writings of Sigmund Freud, tr. por Dr. A. A. Brill (New York: The Modern Library, 1938), p. 633-803. 
final de la relación. Allí reaparece fugazmente, citadas sus palabras por el narrador-autor implícito;" " Ruempo - dijo- la guitarra/ $\mathrm{Pa}_{\text {a }}$ no volverla a templar;/ ...Pues naides ha de cantar/ Cuando este gaucho cantó" " (1. 2275-2276 .. 2279-2280). La historia de Cruz se podría leer como la historia reprimida de Martín Fierro, como si los dos personajes configuraran uno solo en conflicto consigo mismo. Las palabras de Cruz son como una respuesta a las de Martín Fierro: "A otros les brotan las coplas/ Como agua de manantial" (1. 1885-1886) responde a aquel, "Las coplas me van brotando/Como agua de manantial" (I. 5354). El lenguaje mismo de Cruz es más ambivalente, menos reprimido, más carnavalesco; a la copla triste de Martín Fierro, "Tuve en mi pago en un tiempo/ Hijos, hacienda y mujer,/ Pero empecé a padecer/ Me echaron a la frontera/ ¡Y qué iba a hallar al volver!/Tan solo hallé la tapera" (1. 280-294), corresponden coplas menos reprimidas de Cruz, "Yo también tuve una pilcha/ Que me enllenó el corazón,/ Y si en aquella ocasión/ Alguien me hubiera buscao,/ Siguro que ma habria hallao/ Más prendido que un botón" (1. 1739-1746). El viaje de Cruz a la frontera fue una de las tantas encomiendas de su 'Comendante', y cuando lo encontró con su mujer, no lo mató a él por viejo, y a ella la abandonó. En contraste, Martín Fierro cuenta que fue llevado a la fuerza a la frontera; que su mujer lo abandonó estando él ausente y que él, sin embargo, la comprendia y. perdonaba. Cruz cuenta que en otra ocasión él fue objeto de la burla de una mujer que sacó a bailar que le cantó unas seguidillas, "Las mujeres son todas/ Como las mulas;/... Que a las aves que vuelan/ Les sacan las plumas" (1. 1957-1958... 1961-1962), y que él mató a un hombre en el alboroto que se armó después. A esto corresponde la historia que cuenta Martín Fierro, que después de encontrar su rancho abandonado y en ruinas, fue a un baile. Allí fue él el que burló a una negra, y luego mató al negro que salió en su defensa.

Es decir que Martín Fierro se retrata como un personaje cuyas cualidades y comportamiento se acercan más a una versión ideal del gaucho, retratado como victima inocente, que sólo al verse abrumado por circunstancias adversas pierde su inocencia, pero que aún así trata de representarse según su ideal de lo que hace un hombre. Este elemento de inocencia agranda la ironía al aumentar la incongruidad tanto entre lo que la autoridad promete y lo que en efecto cumple dentro de la ficción, como la incongruidad entre lo que el narrador canta (como observador de sí mismo que ya conoce su historia) y lo que muestra (lo que piensa él como víctima dentro de su ficción).

La máscara inónica de Cruz cantor es distinta de la de Martín Fierro, 
porque él no se representa como una víctima inocente en su ficción, sino como víctima bien consciente de lo que está ocurriendo, "Yo sé hacerme el chancho rengo/ Cuando la cosa lo esige... A mí no me matan penas/ Mientras tenga el cuero sano" (1. 1703-1704... 1711-1712). Su ironía se acerca más al sarcasmo o ironía transparente de Fierro y el napolitano. Cruz, si bien es víctima de la autoridad, "Era el Gefe y ya se vé/ No podía competir yo" (1. 1785-1786), consigue invertir los papeles dentro mismo de la ficción, y además de caricaturizar a la autoridad desde su canción: al comandante, "Cuando lo pillé junto al jogónal/ Abrazándome a la china" (1.1811-1812), lo describe con cara "De ternero mal lamido" (1. 1814); le advierte burlonamente, "Cuidao no te vas a pér... tigo,/ Poné cuarta pa salir" (1. 1823-1824); y cuando el viejito aprovecha una distracción para esconderse en un "noque de lejía", Cruz dice con sorna, "iQuién sabe cómo estaría/ Del susto que había llevao!... una cosa tan jedionda/ senti yo, que ni en la fonda/ He visto tal jedentina" (1. 1853-1854 ... 1858-1860). Es un mundo, carnavalesco en que la autoridad es criminal; el traseto ocupa el lugar de la cabeza; el sexo se exalta. El Juez, necesitado de gente, lo transforma a Cruz de un criminal fugitivo en "soldao de Polecía./ Y me largó una proclama/ Tratándome de valiente,/ Que yo era hombre decente" (1. 2052-2055). La incongruidad surge porque Cruz es un criminal, lo cual se invalida con una declaración ("un proclama/ Tratándome de valiente") y. un nombramiento. Esto a su vez cede a una segunda ironía, ya que a un nivel se acepta la falacia que las palabras, más bien el título cambian al hombre, lo cual a otro nivel sirve de comentario sobre el tipo de individuo que representaba la autoridad. Es decir que el canto y la ficción de Cruz representan a la vida humana en su aspecto de risa no oficial, proscrita.

En realidad, la historia de Cruz, incrustada en la ficción de Martín Fierro, se puede leer como una parodia de la ficción de Martín Fierro: es una escritura (ficción cómica, carnavalesca) en oposición a otra escritura (ficción seria: la de Martín Fierro) que permanece en filigrana: son dos textos que se unen, se contradicen, se relativizan en el dialoguismo esencial del carnaval.

"Ironic literature," dice Frye, "begins with realism and tends toward myth, its mythical patterns being as a rule... suggestive of the demonic."12 En efecto, las imágenes que caracterizan la estadía de Martín Fierro entre los indios son análogas a lo demoníaco. El mundo bumano está polarizado; por un lado se sugiere la presencia de un tirano inescrutable, "Dentra al centro un indio viejo/ $\mathrm{Y}$ alli al lengüetiar se larga;/ iQuién sabe qué les

12 Northrop Frye, Anatomy of Criticism (Princeton, New Jersey, 1957), p. 140 . 
encarga!" (2. 265-267), despiadado, "El indio, el cerdo y el gato/ Redaman sangre del hijo" (2. 737-738), melancólico, "El indio nunca se ríe" (2.571), y de una voluntad insaciable; el otro polo está representado por el phamakós, que debe morir para fortalecer" a los otros, "Había un gringuito cautivo/ Que siempre hablaba del barco,/ Y lo augaron en un charco/ Por causante de la peste" (2. 853-856). La relación erótica es destructiva y la relación social es la de la chusma que busca una víctima, "No tiene cariño a naides/ $\mathrm{Ni}$ sabe lo que es amar... Hacen un cerco de lanzas,/ Los indios quedan ajuera;/ Dentra la china ligera/ Como yeguada en la trilla/... Adentro muere la china,/ Sin que aquel círculo rompa" (2. 721-722 . . 745-748 . . 755-756). El mundo animal se representa con animales feroces, que Martín Fierro compara con el indio, "Tiene la vista del águila,/ Del león la temeridá; En el desierto no habrá/... fiera de que no aprienda/ Un instinto de crueldá... Hasta los nombres que tienen/ Son de animales y fieras" (2. 559-565... 593-594). El mundo vegetal es un desierto, "El mal es árbol que crece/ $\mathrm{Y}$ que cortado retoña... La tierra es madre de todos,/ Pero también da ponzoña" (2. 343-344... 347-348). La lanza, el látigo pueden verse como modulaciones del árbol demoníaco. El mundo inorgánico queda sin labrar, con sus rocas y terrenos baldíos, "No sabe aquel indio bruto/ Que la tierra no da fruto/ Si no la riega el sudor" (2. 604-606). Correspondiéndose con el templo apocalíptico se encuentra la cárcel, "De noche formaban cerco/ $\mathrm{Y}$ en el centro nos ponían;/ Para mostrar que querian/Quitarnos toda esperanza/ Ocho o diez filas de lanzas/Alrededor nos hacían" (2.295-300). El camino es un laberinto, imagen de la desorientación del que está perdido, que es lo que dibuja Martín Fierro al cruzar el desierto. Imágenes análogas al mundo demoníaco se encuentran también en la vida de Martín Fierro en la frontera, y caracterizan en mayor a menor grado, los relatos de los otros gauchos cantores.

Dientro de su ficción, Martín Fierro sigue una trayectoria a través del desierto parecido al que ya había hecho a la frontera. Empieza nuevamente como víctima inocente que espera encontrar mejor vida basado en algo que oyó, esperanza que se invalida en la experiencia. Después de matar a un indio tiene que elegir entre morir a manos de los otros indios o de arriesgar la vuelta a una sociedad que lo buscaba por criminal y desertor. Es decir que a un nivel de la ironía vuelve a ser la víctima consciente de su condición, y al otro nivel se produce nuevamente una oposición paradójica en que la víctima tiene que escoger entre dos males. Se lo ve a la víctima atrapada en una situación imposible, de la que aparentemente no hay escapatoria, por lo que el observador (lector implícito) y el ironizador (Martín Fierro-cantor) vuelven a encontrarse comprometidos en la 
ironía. La contradicción básica entre la naturaleza humana y la condición humana no se puede resolver. Se suma a los males de Martín Fierro el hecho de que el Moreno, vencido en la payada, lo estará esperando a la vuelta de cualquier pulpería para vengar la muerte de su hermano. El acto de cambiar de nombre, según nos lo confirma Borges en su cuento "El fin"13 sólo fue una medida paliativa.

Dejando de lado los relatos de los dos hijos de Martín Fierro, de Picardía y la payada entre Martín Fierro y el Moreno, que serían motivo de extensos apartes, y que tal vez tendrían mucho de repetitivo, me limitaré a resumir lo dicho hasta ahora y a finalizar el ensayo con su debida conclusión.

Este trabajo se inició con una lectura-escritura de Martin Fierro en que, comenzando por el escritor y lector históricos, se siguió una trayectoria desde la periferia del texto hacia su centro mismo, analizando las varias relaciones entre autor implícito-lector implícito, autor implícito-escritura, gaucho cantor-gaucho actor, con el fin de desenmascarar el texto. Siguiendo un camino inverso, se puede recapitular lo escrito de la siguiente manera: dentro de su ficción el gaucho es víctima, a veces más (Martín Fierro) a veces menos (Cruz) inocente de la autoridad, que lo trata como un objeto útil para sus fines; a este nivel de la escritura la autori$\mathrm{dad}$ es el ironizador que promete una cosa que queda invalidada en los hechos. El gaucho cantor a su vez, lleva puesta esa máscara de la sátira que es la ironía, y "reality corrects appearance"14 porque Ia intención declarada del gaucho cantor ("appearance") de consolarse cantando sus penas resulta en una exhibición en el escenario de la ficción de la corrupción de la autoridad ("reality"). El autor implícito a su vez, sólo aparece al final de cada parte de su escritura: la primera vez la máscara de gaucho apenas se transparenta, su intención irónica apenas se deja entrever, pero como "la intención irónica de por sí no hace que un texto sea irónico para el lector"'15 cuando aparece este autor implícito al final de su "libro", se hace más explícito: la máscara se transparenta. Sugiere una doble lectura de su escritura: para el lector gaucho, con el que se identifica, una parodia de su propia vida. Al tomar cierta consciencia de su situación irónica como víctima de una autoridad que le priva de autodeterminación, el lector-espectador-implícito-gaucho podrá desprenderse en alguna medida de su condición al convertirse en un observador irónico de sí mismo. Es la única ironía permitida al que está atrapado en una situación imposible. Para el lector-implícito-culto el autor implícito le

\footnotetext{
13 Jorge Luis Borges, Ficciones (Buenos Aires: Emecé, 1956), p. 177-180.

14 Muecke, p. 53.

15 Ibid, p. 57, trad. mía.
} 
insinúa una lectura satírica de su escritura, lectura cuya intención es "through laughter and invective, to cure folly and to punish evil; but if it does not achieve this purpose, it is content to jeer at folly and to expose evil to bitter contempt." 16

En conclusión, lo que el autor implícito se propuso lograr a lo largo del plano sintagmático ${ }^{17}$ de la escritura, es decir a lo largo de esa cadena linear e irreversible del lenguaje, era un cambio de signos, es decir, fundamentalmente que el significante gaucho dejara de tener ese significado relacionado con la irrisión (en la literatura), con la indiferencia y el desprecio en la sociedad. Eso lo obtuvo haciendo que en el plano sistemático de la narración, es decir, en el plano de unidades asociadas en la memoria, que forman grupos que se pueden relacionar, el gaucho se asociara con actividades que si bien a veces lo enaltecían, más a menudo justificaban o invalidaban sus malas acciones debido a la presencia de otros signos, como la 'autoridá' (con sus variantes de Comisario, Juez de Paz, etc.). Normalmente el significante autoridad tiene significados asociados con ley, justicia, inclusive crédito y fe que se da a una persona o cosa en determinada materia. En Martín Fierro, en el plano sistemático del texto, la autoridad adquiere un significado cruel, siniestro, hasta demoníaco, y el gaucho deja de ser objeto de risa, por un lado, y por el otro se lo ve en una situación social imposible que exige cambios. Es decir que los signos se invierten.

ELsa K. GambarinI

Yale University.

16 Highet, p. 234.

17 Este concepto de los dos ejes del lenguaje se encontrará explicado en detalle en Roland Barthes, Writing Degree Zero and Elements of Semiology, trad. por Annette Lavers y Colin Smith (Boston: Beacon Press, 1970), p. 58-88. 